\title{
The Profiling of Design Product Using Bezier Curve for Customers Product Design Preferences
}

\author{
Yuhazri M.Y ${ }^{1^{*}}$, Hidayah W.N ${ }^{2}$, Kamarul A.M ${ }^{1}$, Haery Sihombing ${ }^{3}$, Tahkims M.S ${ }^{4}$, \\ Shamsudin Sulaiman ${ }^{4}$, \\ ${ }^{1}$ Faculty of Manufacturing Engineering Universiti Teknikal Malaysia Melaka, Hang Tuah Jaya, 76100 Durian \\ Tunggal, Melaka, Malaysia, yuhazri@utem.edu.my \\ ${ }^{2}$ Faculty of Technology Management and Technopreneurship Universiti Teknikal Malaysia Melaka, Hang Tuah \\ Jaya, 76100 Durian Tunggal, Melaka, Malaysia \\ ${ }^{3}$ Centre for Languages and Human Development Universiti Teknikal Malaysia Melaka, Hang Tuah Jaya, 76100 \\ Durian Tunggal, Melaka, Malaysia \\ ${ }^{4}$ Faculty of Mechanical Engineering, Universiti Putra Malaysia, 43400 UPM Serdang, Selangor Darul Ehsan \\ Malaysia
}

\begin{abstract}
This study is about the design properties of product based on the customer needs using Customer satisfaction, Kansei Engineering, Bezier Curve and Semantic Differential. To identify, investigate, and determine what are characteristics of products required by customer preferences compared to the image manipulated of product into Bezier curves. This study use 20 sedan cars (front view) that are manipulated into Bezier curve to find out which cars design are customers most preferred. From the data gathered, the most preferred Kansei words for sedan car are Luxury meanwhile for car preferences are BMW 5 Series, BMW F80 and Mercedes Benz E.
\end{abstract}

Key words : Kansei Engineering, Bezier curve, Kansei words, Semantic Differential, Customer Satisfaction.

\section{INTRODUCTION}

Nowadays, there are many various types of consumers' products in international market plunge into discouraging responses; far from what designers expected in their business strategy and plan. There are, however not all good products in the market to have successful in the eyes of their customers to receive good response.

The satisfaction of customer has turned into a key component in business strategy and at the highest priority list of each company[1]. Due too many factors and features made consumers to choose certain product with various reasons (since they have the alternatives of what their need that is provided from other designer), one of the reasons that customer choose the product is aesthetics of product and design that has critical social ramifications [2].
Since the existences of products are, now, not only influencing customers' impressions to functionalities but also quality, and usability of product, product's appearance also should have stylish and typical worth for consumers.

In addition, since product appearances is a major factors influenced consumers' purchasing decision, various investigations are made on systematic product design to obtain a better information about subjective perceptions of consumer [3]. Clearly, the customers are strict in choosing products according to their demand and preferences. Since companies hard to find on how to determine consumers' needs and requirements, it is an unreasonable strategy to fulfill consumers by a single offer. Here, affective engineering is a field of product designs towards the interpretation of consumers' affections for a product into configuration components [4]-[5]'. Affective engineering or Kansei Engineering is one of the main elements applied within manufactured products as an emotional reactions and a key component in choosing whether to purchase or not [6]. Kansei Engineering is viewed as the particulary strategy that has been created to measure and analyze the emotional needs of customers and fuse them in the design process [7], the profile design is a combination of robust product features, design and user should be defined in determining the needs of consumers towards each of products launched to market to attract them and to ensure the product launched well received and recognized in the global market.

In this millennium era, the new competitive obstacles faced by designer and manufacturer are related to their capabilities to comprehend customer's desire and their abilities to create more pleasurable products that meet customer requirements. To customer satisfaction, it emphasized about successful products is as an idea of business from customers' point-of-view that is not enough only through a good design and quality that met customer requirements [8].

Through Kansei Engineering, the designers are able to utilize the inherent cognitive perspective in producing new products that will suit diverse ways of life. Basically, the approach of 
Yuhazri M.Y et al., International Journal of Advanced Trends in Computer Science and Engineering, 8(1.3), 2019,214 - 218

Kansei Engineering method is through summing up the data about all the great part of sense, image, notices, tastes, and sounds the best [9]. It allows the determination of connections between design components and emotion.

The using of Kansei Engineering in product design development connected to catch consumer's most desired sentiments or images into physical configuration components [10]. Harada [11] said that Kansei is an interior process (a high capacity) of the cerebrum that is included in the development of natural response to external stimuli [12].

Since a knowledge about visual properties has potential to be aesthetically experienced or affect aesthetic preference [14], the consumers' aesthetic appraisal of products (that depends on the presence of certain product design properties in the product design) faces many issues related to consumers' requirements. The useful approach towards affective requirements should be, therefore, seen as the possibilities connection to primary relevance of customer satisfaction. On this issues, since the adaption-innovation principle is emphasized with cognitive design, it will show some sort of inclination answers which can be hard-wired to behavior selected stimuli. Briefly, the experimental review towards cognitive value determination against feelings is required to incorporate many frequently encountered feelings [14].

There are gap between users subjective sensitivity (impression, image and feeling) degree and the corresponding value in the database, for companies (manufacturers) to having the capacity that meet customers' satisfaction is therefore through the consumers' affective responses towards the appearance of a product through the model that is focused on the qualitative evaluation scale which require multi-criteria decision-making problem [15]. However, the application of this knowledge in design flied is, however non-structural and complex. It is difficult to be categorized and applied universally since this is no simple principle [16]. On the past research, people theoretically to prefer typical over less typical objects because people tend to enjoy what suits their current knowledge [17]. In short, on how the products are able to convey useful attributes and give a quality impression (practical esteem), beside can impact convenience (ergonomic worth). The presence of a product should influence customer decision in a someway.

A Bayesian Network is a combination of graphical models and Bayesian statistics. Based on history, Bayesian networks can therefore be divided into 2 parts. First, related to the history based on perspectives of the statistical and mathematical background. In the implementation of Bayesian network, generally they consists of the building relationship. The relationship between $n$ variables can be built with the help of expert, from observation data or from a combination both. If it were given $n$ variables and a set of observation data, all of the relationships may have to be determined.

In the beginning periods of CAD/CAM advancement, geometric models needed accuracy in making free frame shapes because of challenges in characterizing geometric articulations [18] in 1980 shaped a strong model and acquired its geometric data through numerically controlled 3 co-ordinate measuring machine. Geometrical impediments can be determined as estimate resilience. New approximations to similar information were additionally attempted by marginally adjusting the discrete information focuses yet [19] saw amid modelization of the bend, such exact controls not really give the coveted outcome on the double and can wind up noticeably monotonous.

\section{MAIN BODY}

\subsection{Experimental Procedures}

This project will conducts the survey, data gathering and analysis. Fig. 1 shows the car design profiling identification and measurement through segmentation. By using segmentation into the 4 quadrants, this study will fitted parameter curve profiling into 2 Bezier curve for each quadrant.

Kansei words are used in the distributed questionnaire with refers to the design of cars. In questionnaire, there are 5 Kansei words that been used for each type of car shown to the respondent for them to rate their preferences towards the design itself. The 5 Kansei words that selected to be used for this study are Stylish, Sporty, Luxury, Comfortable and Safety. The questionnaires is about choose the Kansei word that represented the design profile. Respondents are required to rate each design of car design profile according to every Kansei words that represent respondent preferences.

In Sedan cars, 20 design types of car taken will be analysed based on shape design related to the front view. Every product designs are then interpreted into Bezier Curve in order to describe what the detail of design profile. The identification conducted on the car design based on the data manipulation for the analysis refer to the results of decision making (Kansei engineering) and profiling the 4 quadrant segmented car product with mathematical approach need to be synthesis based on what the characteristic of mathematical equation itself compared to the preferences of product.

Every cars design, are measured by using equation of Bezier curve. The value of $\mathrm{n}$ in the equation are 1 until 8 represents of each $\mathrm{x}$-axis and $\mathrm{y}$-axis. The equation as follows:

$$
\mathrm{B}_{\mathrm{n}}(t)=\mathrm{A}_{\mathrm{n}}(1-t)^{3}+3 \mathrm{~B}_{\mathrm{n}}(1-t)^{2} \mathrm{t}+3 \mathrm{C}_{\mathrm{n}}(1-t) \mathrm{t}^{2}+\mathrm{D}_{\mathrm{n}} t^{3}
$$


Yuhazri M.Y et al., International Journal of Advanced Trends in Computer Science and Engineering, 8(1.3), 2019,214 - 218

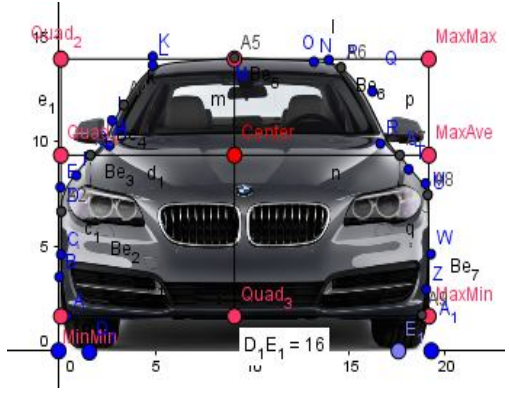

Figure 1: Profiling the Segmented of Product Car Design (Front View) to find out Mathematical Equation

\section{RESULTS}

Table 1 shows the name of 20 sedan car in order to find the car design preferences. Based on the survey distributed to 171 respondents, the 6 car design that has highest number of choice is Audi S6 Avant (Front view 1), BMW 5 Series (Front view 2), BMW F80 M3 (Front view 3), Mazda 3 (Front view 4), Mercedes Benz E Class (Front view 5) and Mitsubishi Lancer (Front view 6).

Table 1: Name of 20 Sedan Car Design

\begin{tabular}{|l|l|l|l|}
\hline No. & CAR BRAND & No. & CAR BRAND \\
\hline 1 & Alfa Romeo & 11 & Kia Quoris \\
\hline 2 & Aston Martin Rapide & 12 & Lexus GS \\
\hline 3 & Audi A4 & 13 & Mazda 3 \\
\hline 4 & Audi S6 Avant & 14 & Mercedes Benz E \\
\hline 5 & BMW 5 Series & 15 & Mitsubishi Lancer \\
\hline 6 & BMW F80 M3 & 16 & Proton Preve \\
\hline 7 & Chevrolet Cruze & 17 & Proton Saga FLX \\
\hline 8 & Ford Mondeo & 18 & Subaru Legacy \\
\hline 9 & Honda Accord & 19 & Toyota Camry \\
\hline 10 & Hyundai Sonata & 20 & Toyota Vios \\
\hline
\end{tabular}

Table 2 shows the result of average value of front view Sedan car from the survey of 171 respondents for the Kansei word. Every words were analysed one by one in order to determine each particular words that would give best representation of designs proposed. The luxury value is the higher average among the 6 design car product. This Luxury is appeared in front view of BMW F80 M3 (Front view 3), while for the Stylish, Comfortable and Safety the higher average also appeared in BMW F80 M3. The higher average for Sporty appeared in BMW 5 Series (Front view 2).

Every 20 car are analyzed one by one using Geogebra software in order to determine each mathematical / parameter equation for each curve towards the best car design. This analysis would give the best preferences of car design. Table 3 shows example of one front view of sedan cars.

Table 2: Average Value of Front View (Sedan Cars)

\begin{tabular}{|l|c|c|c|c|c|}
\hline & STYL & COM & SAFE & SPORT & LUX \\
\hline FV1 & 4.40 & 4.49 & 4.51 & 4.29 & 4.59 \\
\hline FV2 & 4.93 & 4.79 & 4.69 & 4.69 & 5.11 \\
\hline
\end{tabular}

\begin{tabular}{|l|l|l|l|l|l|}
\hline FV3 & 5.09 & 4.87 & 4.80 & 4.67 & 5.19 \\
\hline FV4 & 3.93 & 4.04 & 4.08 & 3.88 & 4.01 \\
\hline FV5 & 4.75 & 4.79 & 4.62 & 4.64 & 4.91 \\
\hline FV6 & 4.18 & 4.29 & 4.31 & 4.43 & 4.26 \\
\hline
\end{tabular}

Table 3: Example of Parameter Curve

\begin{tabular}{ccccc|cccc}
\hline & \multicolumn{4}{c|}{ X-Axis } & \multicolumn{4}{c}{ Y-Axis } \\
\cline { 2 - 9 } & $\mathrm{A}_{1}$ & $\mathrm{~B}_{1}$ & $\mathrm{C}_{1}$ & $\mathrm{D}_{1}$ & $\mathrm{~A}_{1}$ & $\mathrm{~B}_{1}$ & $\mathrm{C}_{1}$ & $\mathrm{D}_{1}$ \\
\hline Be 1 & 0.46 & 0.04 & 0.12 & 0.13 & 1.65 & 3.53 & 4.6 & 6.66 \\
$\mathrm{Be}$ 2 & 0.13 & 0.09 & 0.92 & 1.64 & 6.66 & 7.82 & 8.39 & 9.35 \\
$\mathrm{Be}$ 3 & 1.64 & 2.62 & 2.76 & 3.37 & 9.35 & 9.81 & 11.0 & 11.8 \\
$\mathrm{Be}$ 4 & 3.37 & 4.87 & 4.87 & 9.10 & 11.75 & 14.1 & 13.7 & 14.0 \\
$\mathrm{Be} 5$ & 9.10 & 13.2 & 14.0 & 14.6 & 14.0 & 13.8 & 13.9 & 13.5 \\
$\mathrm{Be}$ 6 & 14.6 & 16.3 & 16.7 & 17.67 & 13.53 & 12.4 & 9.90 & 9.35 \\
$\mathrm{Be} 7$ & 17.7 & 18.1 & 19.0 & 19.11 & 9.35 & 8.67 & 8.00 & 7.45 \\
$\mathrm{Be}$ 8 & 19.1 & 19.3 & 19.0 & 18.82 & 7.45 & 4.62 & 2.93 & 1.71 \\
\hline
\end{tabular}

After all value of parameter curve related to Bezier equation of 20 cars design are collected, this study will determined the overall average values for 20 car as a normalization range. To find the range between maximum and minimum values of every 20 cars by deducting the maximum values to minimum values as described in equation below:

Max - Min $=$ Range $($ Individual range $)$

Then, to make average normalization, this study calculates all of the single range of every parameter Bezier curve by dividing the total of range.

$$
\sum \frac{\text { Range }}{\mathrm{x}}=\text { overall range }
$$

To find segmentation of every parameter, evert individual range need to be divide with overall range as describe in below equation.

$$
\frac{\text { Range individual }}{\text { Overall range }}=\mathrm{y}
$$

After that, to get normalization distance (A) then the single individual range needs to be divided with $\mathrm{y}$,

$$
\frac{\text { Range }}{\mathrm{y}}=\text { normalization distance }=\mathrm{A}
$$

The last, to make segmentation of every parameter of single individual Bezier curve, the individual minimum of every parameter Bezier curve should be added with the value A. This step will continue until get the maximum value.

$$
\begin{array}{ll}
\mathrm{Min}+\mathrm{A}=\mathrm{W} & \text { (Range 1) } \\
\mathrm{W}+\mathrm{A}=\mathrm{B} & \text { (Range 2) } \\
\mathrm{B}+\mathrm{A}=\mathrm{C} & \text { (Range 3) }
\end{array}
$$

Table 4 show the range for Bezier 1 for the 6 car design preference. For the Bezier 2 until Bezier 8, the steps are same as above to get the range value. 
Yuhazri M.Y et al., International Journal of Advanced Trends in Computer Science and Engineering, 8(1.3), 2019,214 - 218

Table 4: Range Bezier 1

\begin{tabular}{lcccc|cccc}
\hline \multirow{2}{*}{ Car Name } & \multicolumn{4}{c|}{ X - Axis } & \multicolumn{4}{c}{ Y - Axis } \\
\cline { 2 - 9 } & $\mathrm{A}_{1}$ & $\mathrm{~B}_{1}$ & $\mathrm{C}_{1}$ & $\mathrm{D}_{1}$ & $\mathrm{~A}_{1}$ & $\mathrm{~B}_{1}$ & $\mathrm{C}_{1}$ & $\mathrm{D}_{1}$ \\
\hline Audi S6 Avant & 3 & 1 & 4 & 2 & 5 & 4 & 1 & 2 \\
BMW 5 Series & 3 & 2 & 2 & 1 & 2 & 5 & 4 & 4 \\
BMW F80 M3 & 2 & 2 & 1 & 3 & 2 & 4 & 4 & 5 \\
Mazda 3 & 4 & 1 & 1 & 1 & 3 & 5 & 4 & 5 \\
Mercedes Benz E & 1 & 2 & 2 & 1 & 4 & 5 & 4 & 4 \\
Mitsubishi Lancer & 4 & 1 & 1 & 2 & 1 & 1 & 3 & 4 \\
\hline
\end{tabular}

From Table 2, the average value of Kansei words will be ranked according to their preferences in Table 5. According to Table 5, the respondents tend to choose front view of BMW 5 Series, BMW F80 and Mercedes Benz E Class based on the higher average of Kansei words.

Table 5: Kansei Words Ranking

\begin{tabular}{|l|c|c|c|c|c|}
\hline & $\begin{array}{l}\text { STY } \\
\text { L }\end{array}$ & $\begin{array}{l}\text { CO } \\
\text { M }\end{array}$ & $\begin{array}{l}\text { SAF } \\
\text { E }\end{array}$ & $\begin{array}{l}\text { SPOR } \\
\text { T }\end{array}$ & $\begin{array}{l}\text { LU } \\
\text { X }\end{array}$ \\
\hline $\begin{array}{l}\text { FV } \\
1\end{array}$ & 4 & 4 & 4 & 5 & 4 \\
\hline $\begin{array}{l}\text { FV } \\
2\end{array}$ & 2 & 2 & 2 & 1 & 2 \\
\hline $\begin{array}{l}\text { FV } \\
3\end{array}$ & 1 & 1 & 1 & 2 & 1 \\
\hline $\begin{array}{l}\text { FV } \\
4\end{array}$ & 6 & 6 & 6 & 6 & 6 \\
\hline $\begin{array}{l}\text { FV } \\
5\end{array}$ & 3 & 2 & 3 & 3 & 3 \\
\hline $\begin{array}{l}\text { FV } \\
6\end{array}$ & 5 & 5 & 5 & 4 & 5 \\
\hline
\end{tabular}

The range of the car preferences for Bezier 1 is listed out (Table 6) where the first column in the range 1, second column and third is range 2, while forth column is range 1 . The sixth column is range 5, and the seventh and last column are in range 4.

Table 6: The Range for Bezier 1 of Car Preferences (Front View

\begin{tabular}{|l|l|l|l|l|l|l|l|}
\hline 3 & 2 & 2 & 1 & 2 & 5 & 4 & 4 \\
\hline 2 & 2 & 1 & 3 & 2 & 4 & 4 & 5 \\
\hline 1 & 2 & 2 & 1 & 4 & 5 & 4 & 4 \\
\hline
\end{tabular}

After all range values are determined, each values collected and used in Geogebra. By using Geogebra, the new curve will be identified through the number of parameter equation.

\section{CONCLUSION}

This study found that the findings of the analysis of the relationship between Kansei words towards the customer's preferences based on the car design. The methods used in this study are Bezier Curve in Geogebra and Kansei Engineering. There are found that the highest value of Kansei words among the 5 Kansei words that been chosen for front view of Sedan car is Luxury. For the car design, the respondents tend to choose front view of BMW 5 Series, BMW F80 and Mercedes Benz E. So, the Kansei word Luxury that most preferred can be related to the new curve of front view. The relations of Kansei Engineering and car preferences were also visible. Further analysis will be performed, as to create the new curve based on the new curve. This is to achieve the research target, which is to formulate guideline that translate human feelings to car design. In the future, consistent effort will be made to apply the proposed for the new curve of car preferences.

\section{ACKNOWLEDGEMENT}

This paper has been greatly enriched by passionate discussion with all people who contributed and the authors would like to thank CRIM-UTeM and RMC-UPM. This study is supported by Research Grant RACE/F3/TK6/FKP/F0030.

\section{REFERENCES}

1. Jianxin J, Yiyang Z, Martin H (2006), A kansei mining system for affective design. Expert System with Application 30, 658-673. https://doi.org/10.1016/j.eswa.2005.07.020

2. Robert W \& Veryzer JR (1993) Aesthetic response and the influence of design principles on product preferences. Advances in Consumer Research 20, 224-228.

3. Chih CY \& Hua CC (2012) Selecting representive affective dimensions using Procrustes analysis: an application to mobile phone design. Applied Ergonomics 43, 1072-1080.

https://doi.org/10.1016/j.apergo.2012.03.008

4. Patrick WJ (2000), Designing pleasurable products: an introduction to the new human factors, 1-224.

https://doi.org/10.1201/9780203305683.ch1

5. Brian H, Cathy B, Rebecca L, Tom C \& Keith E (2006), Affective consumer requirements: a case study of moisturizer packaging. Journal Concurrent Engineering 14, 187-196. https://doi.org/10.1177/1063293X06068358

6. Kim FP \& Shirley YC (2008), Modern - day perception of historic footwear and its links to preference. Journal of Applied Statistics 35, 161-178. https://doi.org/10.1080/02664760701775498

7. Alex B, Arantxa GH, Amaia BA, Kansei engineering: the influence of the scale in the application of the semantic differential, Proceeding from $13^{\text {th }}$ International Congress on Project Engineering, (2009) 452-462.

8. Nattapong K (2012), Emotional design approach to design teak wood furniture. The Asia Pacific Industrial Engineering \& Management Systems Conference, 805-812.

9. Rajkumar R, Michael G \& Kieran K (2009), User-centric design and Kansei engineering. CIRP Journal of Manufacturing Science and Technology 1, 172-178.

https://doi.org/10.1016/j.cirpj.2008.10.007 
Yuhazri M.Y et al., International Journal of Advanced Trends in Computer Science and Engineering, 8(1.3), 2019,214 - 218

10. Chun JC \& Kuohsiang C (2006), Multiple Kansei images in product form design. International Conference in Lisbon, 1-15.

11. Harada A (1998), On the definition of Kansei. In Modelling the Evaluation Structure of Kansei Conference 2, 1-22.

12. Pierre L \& Toshimasa Y (2007), Interdisciplinary design method for eco-design: Introduction Kansei research for design eco-design. In Proceeding of: $5^{\text {th }}$ International Symposium on Environmentally Consious Design and Inverse Manufacturing Ecodesign.

13. Helmut L, Benno B, Andries O \& Dorothee A (2004), A model of aesthetic appreciation and aesthetic judgements. Bristish Journal of Psychology 95, 489-508.

https://doi.org/10.1348/0007126042369811

14. Minu K \& Nitika G (2010), Aesthetic principles and cognitive emotion appraisals: How much of the beauty lies in the eye of the beholder? Journal of Consumer Psychology 20, 485-494. https://doi.org/10.1016/j.jcps.2010.06.015

15. Van NH, Yoshiteru N \& Hongbin Y (2010), A comparative study of target-based evaluation of tradition craft pattern using Kansei data. Knowledge Science and Management, 160-173. https://doi.org/10.1007/978-3-642-15280-1_17

16. Yannlong L (2012), A grey style description framework analysis of design strategy in diy power tools. Advance in Information Sciences \& Service Science 4.

https://doi.org/10.4156/aiss.vol4.issue5.17

17. Robert W \& Veryzer JR (1993) Aesthetic response and the influence of design principles on product preferences. Advances in Consumer Research 20, 224-228.

18. Shinji K, Fumihiko K \& Toshio S (1980), Generation of NC commands for sculptured surface machining from 3 coordinate measuring data. Annals of the CIRP $29,369-372$. https://doi.org/10.1016/S0007-8506(07)61353-5

19. Yves M, Tony L, Jean MC \& Henri G (1998), A shape controlled fitting method for Bezier curves. Computer Aided Geometric Design 15, 879-891

https://doi.org/10.1016/S0167-8396(98)00025-9 